\title{
Analisis Konfigurasi Bahan Bakar Terhadap Produktivitas Fisil pada Fast Breeder Reactor (FBR)
}

\author{
Ainul Mardiyah*, Dian Fitriyani* \\ Laboratorium Fisika Nuklir, Jurusan Fisika \\ Fakultas Matematika dan Ilmu Pengatuhan Alam Universitas Andalas \\ Kampus Unand Limau Manis, Padang, 25163 Indonesia \\ *Ainulmardiyah404@gmail.com
}

\begin{abstract}
ABSTRAK
Analisis konfigurasi bahan bakar terhadap produktivitas fisil pada Fast Breeder Reaktor (FBR) telah dilakukan. Konfigurasi bahan bakar dirancang dalam 5 variasi dengan 2 kategori yaitu konfigurasi homogen (inner dan outer) serta heterogen dengan fraksi bahan bakar yang sama yaitu $45 \%$. Perhitungan dilakukan dengan metode komputasi menggunakan kode FI-ITB.CHI yang dikembangkan dalam bahasa pemrograman Borland Delphi 7.0 Bahan bakar yang digunakan adalah campuran uranium-plutonium nitrida (Un-PuN) dan pendingin timbal bismuth $(\mathrm{Pb}-\mathrm{Bi})$ pada teras reaktor 2-D (dua dimensi) geometri $\mathrm{r}-\mathrm{Z}$ (silinder). Hasil perhitungan difusi neutronik menunjukkan bahwa pada semua konfigurasi bahan bakar yang diamati diperoleh nilai kritikalitas teras melalui pengaturan fraksi pengayaan (enrichment) pada setiap bagian teras. Fraksi pengayaan rata-rata yang terkecil untuk mencapai keadaan kritis ditunjukkan pada konfigurasi homogen-outer. Hasil analisis menunjukkan bahwa nilai distribusi fluks neutron yang paling tinggi diperoleh pada konfigurasi heterogen dan nilai distribusi daya dengan nilai power peaking factor (ppf) terendah diperoleh pada konfigurasi homogen. Nilai densitas atom bahan fisil yaitu ${ }^{239} \mathrm{Pu}$ paling besar peningkatannya terjadi pada konfigurasi homogen-inner 2 sebagai hasil reaksi fisi bahan bakar setelah 1 siklus (4 tahun) operasi. Nilai BreedingRatio (BR) untuk seluruh konfigurasi bahan bakar masih dalam rentang nilai yang diharapkan $(B R>1)$ namun nilai BR paling baik ditunjukkan pada konfigurasi homogen-inner 2 yaitu dengan nilai 1,17 .

Kata kunci: FBR, konfigurasi bahan bakar, fisil, breeding ratio.
\end{abstract}

\section{ABSTRACT}

Analysis of fuel configuration on fissile productivity at the Fast Breeder Reactor (FBR) has been carried out. The fuel configuration is designed in 5 variations with 2 categories namely homogeneous (inner and outer) configurations and heterogeneous with the same fuel fraction of $45 \%$. Calculation is conducted by computational method using FI-ITB.CHI code which is developed with Borland Delphi 7.0 programming language. Using a mixture of uranium-plutonium nitride (Un-PuN) and bismuth (Pb-Bi) lead coolers on the 2-D reactor core (two dimensions) $r-z$ (cylinder) geometry. The results of neutron diffusion calculations show that in all fuel configurations observed core values were obtained by setting enrichment fractions (enrichment) on each part of the terrace. The smallest average enrichment fraction to achieve a critical state is shown in the homogeneous-outer configuration. The results of the analysis show that the highest neutron flux distribution values are obtained in heterogeneous configurations and power distribution values with the lowest value of power peaking factor (ppf) obtained in a homogeneous configuration. The atomic density value of fissile material is ${ }^{239} \mathrm{Pu}$, the greatest increase occurs in the homogeneous-inner 2 configuration as the result of fuel fission reaction after 1 cycle (4 years) of operation. The breeding ratio (BR) for all fuel configurations is still within the range of expected values $(B R>1)$ but the best BR value is shown in the homogeneous-inner 2 configuration, which is 1.17.

Key word: FBR, fuel configuration, fissile, breeding ratio.

\section{PENDAHULUAN}

Reaktor pembiak cepat (Fast Breeder Reactor, FBR) merupakan jenis reaktor cepat yang dirancang untuk memproduksi bahan fisil yang lebih banyak daripada bahan fisil yang digunakan. Dalam banyak disain FBR, bahan bakar (fuel) dikelilingi oleh selimut (blanket) yang berisi bahan fertil ${ }^{238} \mathrm{U}$ yang akan menangkap neutron cepat dari reaksi fisi, sebagian akan dikonversi menjadi ${ }^{239} \mathrm{Pu}$ yang dapat digunakan sebagai bahan bakar nuklir pada reaktor pembiak cepat. Bahan bakar yang biasanya digunakan dalam reaktor pembiak cepat adalah campuran uranium plutonium nitrida (Un-PuN), uranium plutonium karbid (UC-PuC) dan oksida (MOX) (Walter dan Reynolds, 1981). Bahan bakar tersebut memiliki titik leleh dan konduktivitas termal yang tinggi. Sedangkan pendingin yang banyak digunakan pada reaktor cepat berupa timbal bismut (Pb-Bi). Karakteristik yang dimiliki $\mathrm{Pb}-\mathrm{Bi}$ yaitu titik lebur $125^{\circ} \mathrm{C}$ 
dan titik didih $1670{ }^{\circ} \mathrm{C}$. Penggunaan $\mathrm{Pb}$-Bi sebagai pendingin memiliki kelebihan dibandingkan dengan sodium dalam hal tidak berbahaya jika berinteraksi dengan udara dan air (Su'ud, 1998).

Telah dilakukan penelitian tentang pengaruh 3 jenis bahan bakar (UN-PuN, UC-PuC dan MOX) terhadap nilai breeding ratio pada reaktor pembiak cepat (Lestari, 2008). Hasil penelitian menunjukkan bahwa untuk penggunaan bahan bakar UN-PuN diperoleh nilai breeding ratio yang stabil. Cinantya dan Fitriyani (2014) melakukan penelitian tentang analisis neutronik pada reaktor cepat dengan variasi bahan bakar (UN-PuN, UC-PuC, dan MOX) dengan hasil penelitian menunjukkan penggunaan bahan bakar UN-PuN pada reaktor cepat berpendingin $\mathrm{Pb}-\mathrm{Bi}$ menunjukkan kinerja neutronik yang optimal. Arisa (2008) melakukan analisis terhadap pembiakan (Breeding) ${ }^{239} \mathrm{Pu}$ dengan variasi geometri teras dan ukuran teras reaktor. Hasil penelitian menunjukkan volume teras reaktor terkecil dengan simetri pipih menunjukkan kinerja yang sangat bagus.

Untuk melengkapi informasi mengenai karakteristik Fast Breeder Reactor (FBR) secara menyeluruh masih banyak aspek yang perlu ditinjau, salah satunya adalah pola atau konfigurasi bahan bakar di teras terhadap produktivitas fisil. Konfigurasi bahan bakar dapat dilakukan dengan berbagai cara yaitu bahan bakar disusun secara homogen (inner dan outer) serta heterogen antara blanket (fertil) dan fisil pada nilai fraksi bahan bakar tertentu. Konfigurasi bahan bakar di teras akan mempengaruhi distribusi fluks neutron di seluruh bagian teras. Pola atau konfigurasi distribusi fluks neutron akan berdampak juga terhadap pembangkitan daya. Selain itu jumlah neutron pada suatu tempat akan mempengaruhi produksi fisil dari bahan fertil (Walter dan Reynolds, 1981).

\section{METODE}

Penelitian untuk menganalisis konfigurasi bahan bakar terhadap produktivitas fisil dilakukan menggunakan kode FI-ITB.CHI yang dikembangkan dalam bahasa pemrograman delphi 7.0. Perhitungan pada penelitian ini diterapkan pada teras reaktor dengan geometri silinder (R-Z). Bahan bakar yang digunakan adalah campuran uranium-plutonium nitrida (UN$\mathrm{PuN}$ ) dengan berpendingin timbal bismut ( $\mathrm{Pb}-\mathrm{Bi})$. Fraksi bahan bakar yang digunakan sebanyak $45 \%$, fraksi cladding $20 \%$ dan fraksi pendingin $35 \%$. Dalam proses perhitungan, agar diperoleh pendekatan dan kesesuaian dengan model teoritis maka dilakukan diskritisasi ruang dalam pembagian teras reaktor berbentuk silinder silinder seperti yang diperlihatkan pada Gambar I. Masing-masing komponen radial dan aksial dibagi dalam 7 daerah (region) dengan lebar bervariasi yaitu cladiing $10 \mathrm{~cm}$ dan reflektor $40 \mathrm{~cm}$ dan tiap daerah dibagi menjadi beberapa mesh.

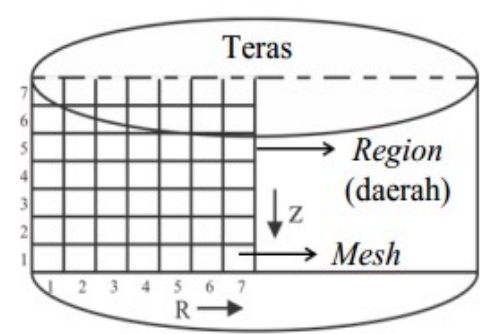

Gambar 1 Diskritisasi ruang r-z

Perhitungan dilakukan pada semua mesh sehingga dapat mewakili teras reaktor secara keseluruhan. Dalam setiap daerah ditempatkan beberapa kelompok bahan atau grup material yang terdiri dari bahan bakar, bahan struktur dan pendingin. Bagian dalam berfungsi sebagai pembangkit energi yang disebut teras aktif yang berisi grup material $\mathrm{C} 1 \mathrm{hingga} \mathrm{C} 5$, dan pada bagian luar ditempatkan bahan reflektor dan blok perisai (shielding). C1 hingga C5 dibedakan berdasarkan fraksi bahan bakar campuran uranium-plutonium nitrida. Terdapat lima variasi bahan bakar yang dibedakan yaitu homogen-outer (blanket ditempatkan bagian luar), homogeninner 1 (blanket ditempatkan di pusat teras arah radial), homogen-inner 2 (blanket ditempatkan di pusat teras arah aksial), heterogen 1 dan 2 (blanket dan fisil disusun secara acak dalam teras). Analisis dilakukan terhadap hasil perhitungan burn-up selama 1 siklus (4 tahun). Model 
konfigurasi yang digunakan dapat dilihat pada Gambar 2 sampai Gambar 6 dimana simbolsimbol dalam setiap kotak menunjukkan grup material dengan keterangan sebagai berikut :

$\mathrm{C} 1$ : core 1 (fisil)
$\mathrm{C} 2$ : core 2 (fisil)
$\mathrm{C} 3$ : core 3 (fisil)
$\mathrm{C} 4$ : core 4 (fisil)

C5 : core 5 (berisi blanket)

Rf : Pin reflektor

Co : pendingin

Sh : Pin shild

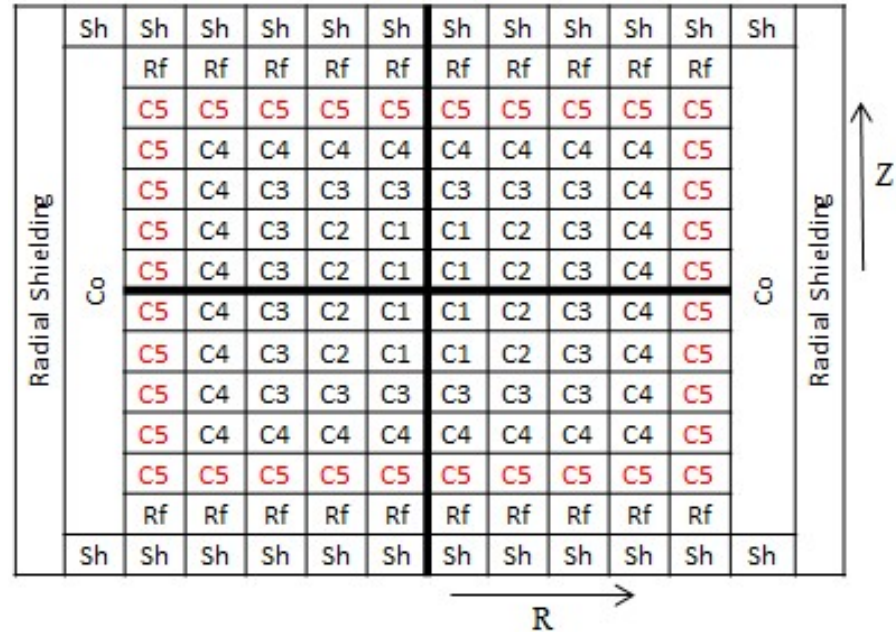

Gambar 2 Konfigurasi teras homogen-outer

\begin{tabular}{|c|c|c|c|c|c|c|c|c|c|c|c|c|c|}
\hline \multirow{14}{*}{ 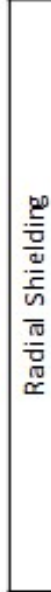 } & Sh & Sh & Sh & Sh & Sh & Sh & Sh & Sh & Sh & Sh & Sh & Sh & \multirow{14}{*}{ 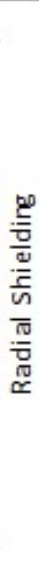 } \\
\hline & \multirow{12}{*}{8} & Rf & Rf & Rf & Rf & Rf & Rf & Rf & Rf & $\mathrm{Rf}$ & Rf & \multirow{12}{*}{8} & \\
\hline & & $\mathrm{C} 4$ & C1 & C1 & C1 & C1 & C1 & C1 & C1 & C1 & $\mathrm{C} 4$ & & \\
\hline & & $\mathrm{C} 4$ & $\mathrm{C} 2$ & $\mathrm{C} 2$ & $\mathrm{C} 2$ & $\mathrm{C} 2$ & $\mathrm{C} 2$ & $\mathrm{C} 2$ & $\mathrm{C} 2$ & $\mathrm{C} 2$ & $\mathrm{C} 4$ & & \\
\hline & & $\mathrm{C} 4$ & $\mathrm{C} 3$ & $\mathrm{C} 3$ & C3 & $\mathrm{C} 3$ & $\mathrm{C} 3$ & C3 & $\mathrm{C} 3$ & C3 & $\mathrm{C} 4$ & & \\
\hline & & $\mathrm{C} 4$ & $\mathrm{C5}$ & C5 & C5 & $\mathrm{C5}$ & C5 & C5 & $\mathrm{C5}$ & C5 & $\mathrm{C} 4$ & & \\
\hline & & $\mathrm{C} 4$ & $\mathrm{C5}$ & C5 & C5 & $\mathrm{C5}$ & C5 & C5 & $\mathrm{C5}$ & C5 & $\mathrm{C} 4$ & & \\
\hline & & $\mathrm{C} 4$ & $\mathrm{C5}$ & $\mathrm{C5}$ & $\mathrm{C5}$ & $\mathrm{C5}$ & $\mathrm{C5}$ & $\mathrm{C5}$ & $\mathrm{C5}$ & $\mathrm{C5}$ & $\mathrm{C} 4$ & & \\
\hline & & $\mathrm{C} 4$ & $\mathrm{C5}$ & $\mathrm{C} 5$ & $\mathrm{C5}$ & $\mathrm{C5}$ & $\mathrm{C5}$ & $\mathrm{C} 5$ & $\mathrm{C5}$ & $\mathrm{C5}$ & $\mathrm{C} 4$ & & \\
\hline & & $\mathrm{C} 4$ & $\mathrm{C} 3$ & C3 & C3 & $\mathrm{C} 3$ & C3 & C3 & $\mathrm{C} 3$ & C3 & $\mathrm{C} 4$ & & \\
\hline & & $\mathrm{C} 4$ & $\mathrm{C} 2$ & $\mathrm{C} 2$ & $\mathrm{C} 2$ & $\mathrm{C} 2$ & $\mathrm{C} 2$ & $\mathrm{C} 2$ & $\mathrm{C} 2$ & $\mathrm{C} 2$ & $\mathrm{C} 4$ & & \\
\hline & & $\mathrm{C} 4$ & $\mathrm{C} 1$ & C1 & C1 & C1 & C1 & C1 & $\mathrm{C} 1$ & C1 & $\mathrm{C} 4$ & & \\
\hline & & $\mathrm{Rf}$ & Rf & $\mathrm{Rf}$ & Rf & Rf & Rf & Rf & Rf & $\mathrm{Rf}$ & $\mathrm{Rf}$ & & \\
\hline & Sh & Sh & Sh & Sh & Sh & Sh & Sh & Sh & Sh & Sh & Sh & Sh & \\
\hline
\end{tabular}

Gambar 3 Konfigurasi teras homogen-inner 1 


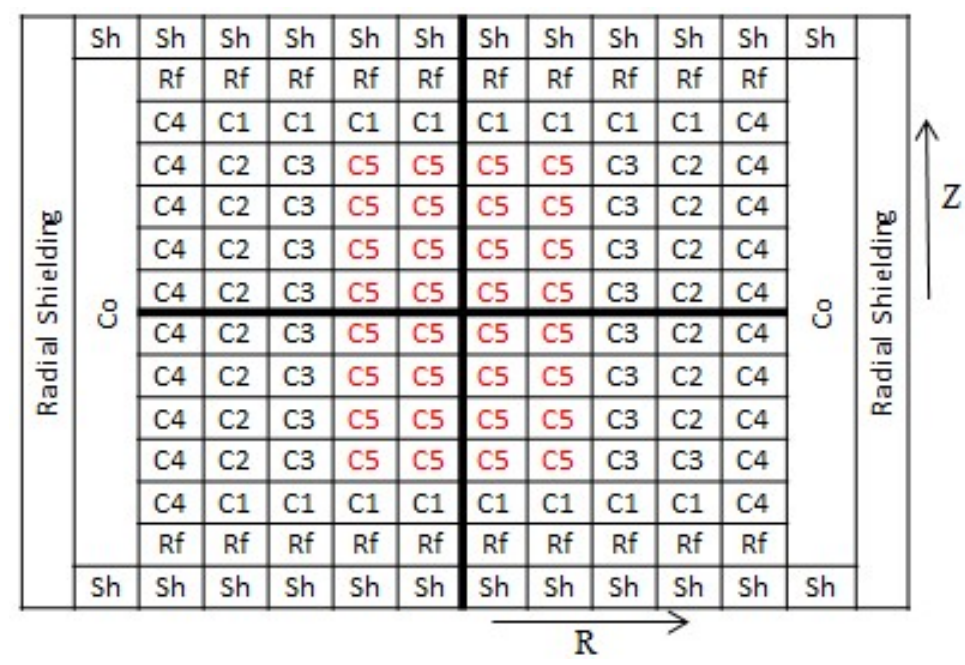

Gambar 4 Konfigurasi teras homogen-inner 2

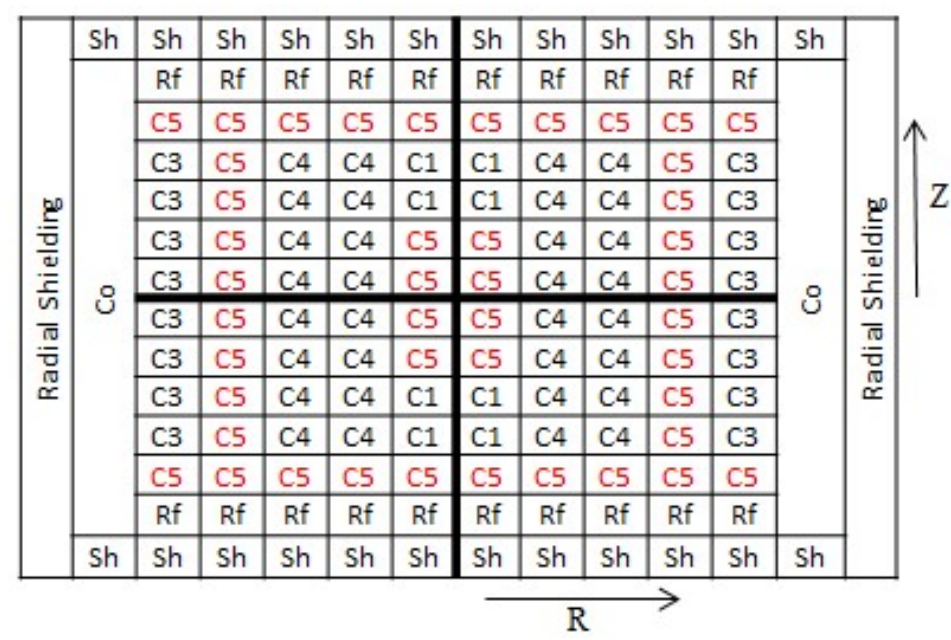

Gambar 5 Konfigurasi teras heterogen-1

\begin{tabular}{|c|c|c|c|c|c|c|c|c|c|c|c|c|c|}
\hline \multirow{14}{*}{ 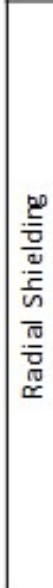 } & Sh & Sh & Sh & Sh & $\mathrm{Sh}$ & Sh & Sh & Sh & Sh & Sh & Sh & Sh & \multirow{13}{*}{ 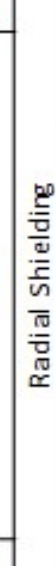 } \\
\hline & \multirow{12}{*}{ ৪ } & $\mathrm{Rf}$ & $\mathrm{Rf}$ & $\mathrm{Rf}$ & $\mathrm{Rf}$ & $\mathrm{Rf}$ & Rf & $\mathrm{Rf}$ & $\mathrm{Rf}$ & \begin{tabular}{|l}
$\mathrm{Rf}$ \\
\end{tabular} & $\mathrm{Rf}$ & \multirow{12}{*}{8} & \\
\hline & & $\mathrm{C} 5$ & C3 & $\mathrm{C} 4$ & $\mathrm{C5}$ & $\mathrm{C} 1$ & C2 & $\mathrm{C5}$ & C3 & C4 & $\mathrm{C5}$ & & \\
\hline & & $\mathrm{C5}$ & C3 & $\mathrm{C} 4$ & C5 & C1 & C2 & C5 & C3 & C4 & $\mathrm{C5}$ & & \\
\hline & & $\mathrm{C} 5$ & C3 & $\mathrm{C} 4$ & C5 & C1 & C2 & C5 & C3 & C4 & C5 & & \\
\hline & & C5 & C3 & $\mathrm{C} 4$ & C5 & $\mathrm{C} 1$ & C2 & C5 & C3 & C4 & C5 & & \\
\hline & & $\mathrm{C} 5$ & $\mathrm{C} 3$ & $\mathrm{C} 4$ & $\mathrm{C5}$ & C1 & $\mathrm{C} 2$ & C5 & C3 & $C 4$ & $\mathrm{C5}$ & & \\
\hline & & $\mathrm{C5}$ & C3 & $\mathrm{C} 4$ & $\mathrm{C5}$ & $\mathrm{C} 1$ & $\mathrm{C} 2$ & $\mathrm{C5}$ & $\mathrm{C} 3$ & $\mathrm{C} 4$ & $\mathrm{C5}$ & & \\
\hline & & $\mathrm{C5}$ & C3 & $\mathrm{C} 4$ & C5 & $\mathrm{C} 1$ & C2 & $\mathrm{C5}$ & C3 & $\mathrm{C} 4$ & $\mathrm{C5}$ & & \\
\hline & & $\mathrm{C5}$ & C3 & $\mathrm{C} 4$ & $\mathrm{C5}$ & $\mathrm{C} 1$ & C2 & $\mathrm{C5}$ & C3 & C4 & $\mathrm{C5}$ & & \\
\hline & & $\mathrm{C5}$ & $\mathrm{C} 3$ & $\mathrm{C} 4$ & $\mathrm{C5}$ & C1 & C2 & $\mathrm{C5}$ & C3 & C4 & $\mathrm{C5}$ & & \\
\hline & & $\mathrm{C5}$ & C1 & $\mathrm{C} 4$ & C5 & C1 & $\mathrm{C} 2$ & $\mathrm{C5}$ & C1 & C4 & $\mathrm{C5}$ & & \\
\hline & & Rf & $\mathrm{Rf}$ & $\mathrm{Rf}$ & Rf & $\mathrm{Rf}$ & Rf & Rf & Rf & Rf & Rf & & \\
\hline & Sh & Sh & Sh & Sh & $\mathrm{Sh}$ & Sh & Sh & Sh & Sh & Sh & Sh & Sh & \\
\hline
\end{tabular}

Gambar 6 Konfigurasi teras heterogen-2 


\section{HASIL DAN DISKUSI}

\subsection{Nilai Faktor Multiplikasi}

Perhitungan difusi neutronik dilakukan untuk mendapatkan harga $\mathrm{k}_{\text {eff }}$ yang diinginkan yaitu kondisi kritis, dengan mengatur fraksi enrichment di setiap bagian nilai teras $\mathrm{k}_{\text {eff }}$ selama satu siklus operasi (4 tahun) untuk masing-masing variasi konfigurasi bahan bakar dapat dilihat pada Tabel 1.

Tabel 1 Nilai faktor multiplikasi pada semua konfigurasi bahan bakar

\begin{tabular}{cccccc}
\hline \multirow{2}{*}{ Tahun } & \multicolumn{5}{c}{$\mathrm{k}_{\text {eff }}$} \\
\cline { 2 - 6 } & $\begin{array}{c}\text { Homogen- } \\
\text { outer }\end{array}$ & $\begin{array}{c}\text { Homogen- } \\
\text { inner } 1\end{array}$ & $\begin{array}{c}\text { Homogen- } \\
\text { inner } 2\end{array}$ & $\begin{array}{c}\text { Heterogen- } \\
1\end{array}$ & $\begin{array}{c}\text { Heterogen- } \\
2\end{array}$ \\
\hline 1 & 1,000907 & 1,000885 & 1,000763 & 1,000882 & 1,000895 \\
2 & 1,000904 & 1,000875 & 1,000770 & 1,000877 & 1,000883 \\
3 & 1,000902 & 1,000867 & 1,000781 & 1,000874 & 1,000874 \\
4 & 1,000899 & 1,000860 & 1,000793 & 1,000871 & 1,000868 \\
\hline
\end{tabular}

Hasil ini menunjukkan bahwa reaktor dalam keadaan kritis selama reaktor dioperasikan dengan pengaturan konfigurasi bahan bakar dan pengayaan (enrichment) di tiap bagian teras sehingga teras reaktor berada dalam keadaan yang stabil.

\subsection{Perubahan Densitas Bahan Bakar}

Selama operasi, beberapa isotop bahan bakar berfisi dan sebagian berubah menjadi unsur aktinida yang lebih tinggi melalui tangkapan neutron. Perubahan densitas bahan bakar ini menjadi sangat penting untuk diamati kerena akan menentukan rasio konversi perubahan bahan fertil ${ }^{238} \mathrm{U}$ menjadi bahan fisil ${ }^{239} \mathrm{Pu}$. Dimana bahan fertil ${ }^{238} \mathrm{U}$ untuk semua konfigurasi mengalami penurunan dan meningkatkan bahan fisil ${ }^{239} \mathrm{Pu}$. Perubahan densitas isotop ${ }^{239} \mathrm{Pu}$ untuk semua konfigurasi bahan bakar dapat dilihat pada Gambar 7.

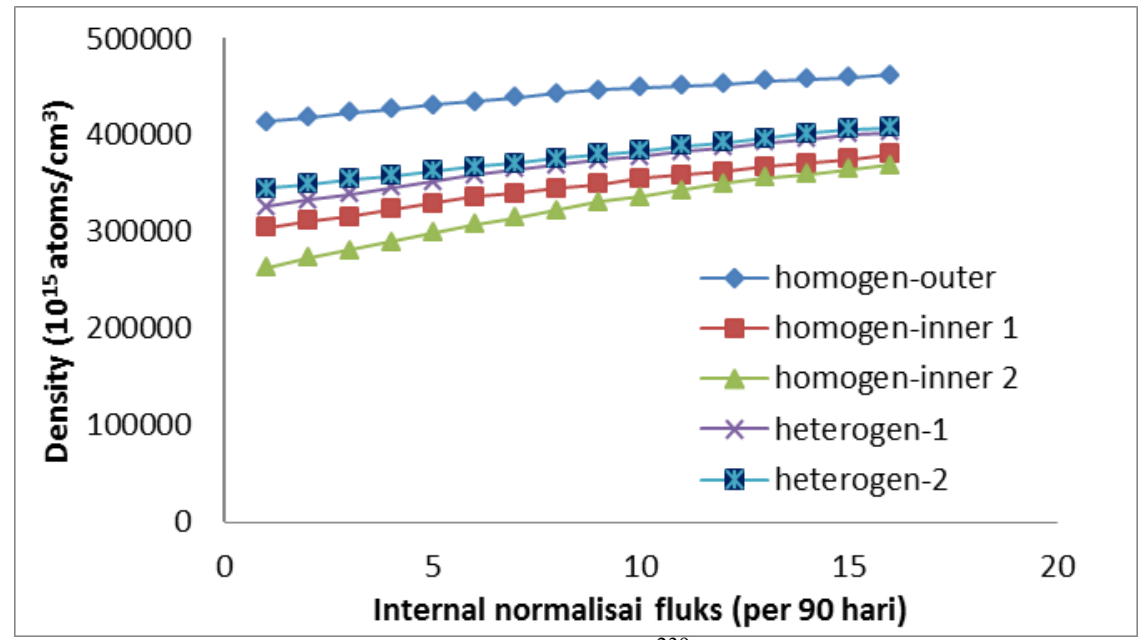

Gambar 7 Densitas atom ${ }^{239} \mathrm{Pu}$ (4 tahun)

Berdasarkan hasil simulasi diketahui bahwa pada semua bentuk konfigurasi bahan bakar homogen-outer, homogen-inner 1, homogen-inner 2 serta konfigurasi heterogen-1 dan heterogen-2 mengalami peningkatan densitas ${ }^{239} \mathrm{Pu}$. Peningkatan ${ }^{239} \mathrm{Pu}$ yang diharapkan apabila grafik meningkat dengan lebih tajam artinya perubahan bahan fertil menjadi fisil semakin lama terjadi semakin cepat.

Konfigurasi bahan bakar homogen-inner 2 adalah reaktor model terbaik dibandingkan empat model lain untuk teras berbentuk silinder dikarenakan perubahan densitas atom ${ }^{239} \mathrm{Pu}$ lebih tinggi dibanding yang lain. 


\subsection{Nilai Breeding Ratio}

Untuk dapat melakukan pembiakkan pada reaktor maka nilai BR yang di harapkan harus lebih besar dari 1 . Nilai BR $>1$ diartikan bahwa bahan fisil lebih banyak daripada bahan fisil yang musnah sedangkan nilai $\mathrm{BR}<1$ terjadi pengurangan produksi bahan fisil dalam reaktor. Hasil nilai BR pada tiap konfigurasi bahan bakar pada simulasi ini terlihat pada Gambar 8 .

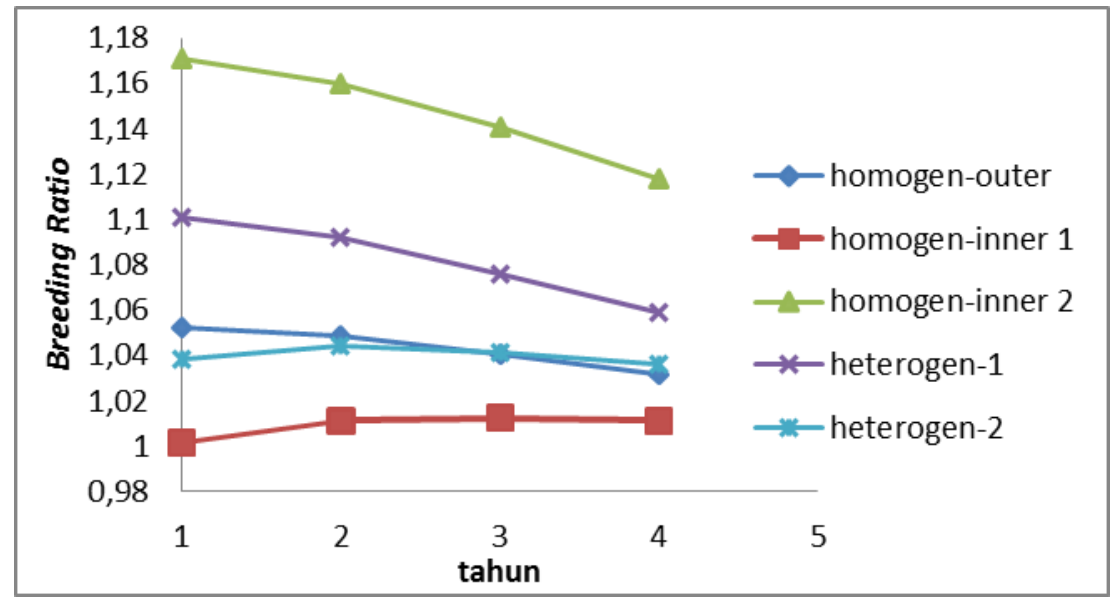

Gambar 8 Breeding ratio

Hasil dari simulasi memperlihatkan bahwa nilai BR yang dihasilkan untuk semua konfigurasi bahan bakar besar dari 1. Hal ini menunjukkan bahwa bahan fisil yang diproduksi lebih banyak daripada bahan fisil yang musnah. Pada konfigurasi bahan bakar nilai BR yang paling besar yaitu homogen-inner 1 namun seiring dengan lamanya waktu operasi nilai BR terus berkurang, artinya bahan fisil yang diproduksi semakin sedikit dibandingkan dengan bahan fisil yang musnah selama terjadi pembakaran di dalam teras, dengan kata lain menunjukkan bahwa reaksi absorbsi semakin dominan dibandingkan dengan reaksi lainnya. Secara keseluruhan nilai BR untuk tiap kofigurasi bahan bakar mengalami pengurangan selama operasi 1 siklus.

Dari semua aspek, secara umum konfigurasi homogen lebih bagus dibandingkan konfigurasi heterogen ditinjau dari breeding ratio, dan desitas atom dimana dengan konfigurasi homogen reaktor bisa bertahan selama 4 tahun bahkan lebih.

\section{KESIMPULAN}

Nilai faktor multiplikasi yang didapatkan pada semua model konfigurasi berada dalam keadaan kritis, dengan pengaturan fraksi enrichment pada setiap interval refueling (4 tahun). Model konfigurasi heterogen-2 menunjukkan nilai distribusi fluks neutron paling besar dan nilai pembiakan (BR) pada semua model konfigurasi menunjukkan angka yang diharapkan yaitu $>1$, yang berarti terjadi pembiakan ${ }^{239} \mathrm{Pu}$.

\section{DAFTAR PUSTAKA}

Arisa, D., Analisis Pembiakan (Breeding) Plutonium-239 pada Reaktor Pembiak Cepat Berpendingin Logam Cair (LMFBR) dengan Variasi Geometri Teras dan Ukuran Teras Reaktor, Skripsi, UNAND, Padang, 2008.

Cinantya, N.D dan Fitriyani, D., Analisis Neutronik pada Reaktor Cepat dengan Variasi Bahan Bakar (UN-PuN, UC-PuC dan MOX), Jurnal Fisika Unand, 3 (1), 1-7, 2014.

Lestari, M.A dan Fitriyani, D., Pengaruh Bahan Bakar (UN-PuN, UC-PuC, dan MOX) Terhadap Nilai Breeding Ratio pada Reaktor Pembiak Cepat, Jurnal Fisika Unand, 3 (1), 1-7, 2014.

Su'ud, Z., FI-Institut Teknologi Bandung: A Computer Code for Nuclear Reactor Cell Homogenization Calculation, Proseding Seminar Ke-7 proc of Computation in Nuclear Science \& Technology, Batan-Jakarta, 1998.

Waltar, A.E. dan Reynolds, A.B., Fast Breeder Reactor, Pergamon Press, U.S.A, 1981. 